\title{
River bulge evolution and dynamics in a non-tidal sea - Daugava River plume in the Gulf of Riga, Baltic Sea
}

\author{
Edith Soosaar, Ilja Maljutenko, Rivo Uiboupin, Maris Skudra, and Urmas Raudsepp \\ Marine Systems Institute at Tallinn University of Technology, Tallinn, Estonia \\ Correspondence to: Edith Soosaar (edith.soosaar@msi.ttu.ee)
}

Received: 1 September 2015 - Published in Ocean Sci. Discuss.: 21 October 2015

Revised: 4 February 2016 - Accepted: 29 February 2016 - Published: 10 March 2016

\begin{abstract}
Satellite remote sensing imagery and numerical modelling were used for the study of river bulge evolution and dynamics in a non-tidal sea, the Gulf of Riga (GoR) in the Baltic Sea. Total suspended matter (TSM) images showed a clearly formed anti-cyclonically rotating river bulge from Daugava River discharge during the studied low wind period. In about 7-8 days the bulge grew up to $20 \mathrm{~km}$ in diameter, before being diluted. A high-resolution (horizontal grid step of $125 \mathrm{~m}$ ) General Estuarine Transport Model (GETM) was used for detailed description of the development of the river plume in the southern GoR over the period when satellite images were acquired. In the model simulation, the bulge growth rate was estimated as $r_{\mathrm{b}} \sim t^{0.5 \pm 0.04}$ $\left(R^{2}=0.90\right)$. Both the model simulation and the satellite images showed that river water was mainly contained in the bulge and there were numerous intrusions at the outer perimeter of the bulge. We performed numerical sensitivity tests with actual bathymetry and measured river runoff without wind forcing (1) having an initial three-dimensional density distribution, and (2) using initially a homogeneous ambient density field. In the first case, the anti-cyclonic bulge did not develop within the course of the model simulation and the coastal current was kept offshore due to ambient densitydriven circulation. In the second case, the river plume developed steadily into an anti-cyclonically recirculating bulge, with $r_{\mathrm{b}} \sim t^{0.28 \pm 0.01}\left(R^{2}=0.98\right)$, and a coastal current. Additional simulations with constant cross-shore and alongshore winds showed a significant effect of the wind in the evolution of the river bulge, even if the wind speed was moderate (3-4 $\mathrm{m} \mathrm{s}^{-1}$ ). While previous studies conclude that the midfield bulge region is governed by a balance between centrifugal, Coriolis and pressure gradient terms, our study showed that geostrophic balance is valid for the entire mid-field of
\end{abstract}

the bulge, except during the $1-1.5$ rotation period at the beginning of the bulge formation. In addition, while there is discharge into the homogenous GoR in the case of a high inflow Rossby number, the river inflow might split into two jets, with strong mixing zone in-between, in the plume nearfield region.

\section{Introduction}

River water entering a coastal ocean typically forms a buoyant plume with an expanding anti-cyclonically rotating bulge near the river mouth and a coastal current in the coastally trapped wave direction (Fong and Geyer, 2002). Coastal currents are favoured in the case of low-discharge conditions and downwelling winds, while bulge formation is favoured during high-discharge conditions and upwelling winds (Chant et al., 2008). The anti-cyclonically recirculating bulge is characteristic of the surface advective plume (Yankovsky and Chapman, 1997), being a prominent feature in rotating tank experiments and numerical simulations under ideal conditions (Avicola and Huq, 2003; Horner-Devine et al., 2006; Thomas and Linden, 2007). Approximately $25-70 \%$ of river water is trapped in the bulge (Fong and Geyer, 2002).

Observational studies confirm that the bulge is a naturally occurring phenomenon with many rivers (Chant et al., 2008; Horner-Devine et al., 2008; Horner-Devine, 2009; Valente and da Silva, 2009; Saldías et al., 2012; Hopkins et al., 2013; Mendes et al., 2014; Pan et al., 2014; Fernández-Nóvoa et al., 2015), but an anti-cyclonic rotation inside a bulge is observed seldom (Kudela et al., 2010; Horner-Devine, 2009; Chant et al., 2008). Observations of the evolution of the bulge over a certain time period are almost non-existent, with the ex- 
ception of the Niagara River plume (Horner-Devine et al., 2008) and the Tagus estuary plume (Valente and da Silva, 2009). However, both cases are without clear evidence of anti-cyclonic circulation within the bulge.

In natural conditions, the evolution of the bulge is affected by properties of the outflow (Yankovsky and Chapman 1997; Avicola and Huq, 2003), tides (Valente and da Silva, 2009), wind (Dzwonkowski and Yan, 2005; Whitney and Garvine, 2005) and the ambient coastal current (Fong and Geyer, 2002). Thus, the evolution of the structure and circulation inside the bulge is difficult to observe. Exploitation of optical satellite remote sensing has extended the possibilities of monitoring and understanding the river plume dynamics under various hydrological, morphological and hydrodynamical conditions. A number of existing papers provide composite maps where plume location and structure are described in response to prevailing wind conditions. Neither the evolution of the bulge nor the anti-cyclonic circulation within it can be identified from the composite satellite remote sensing images. Although each river plume can be considered as specific, Horner-Devine et al. (2015) have summarized the dynamics of an anti-cyclonically rotating bulge, with special emphasis on the river water volume recirculating within the bulge. In their study, with reference to Nof and Pichevin (2001), they summarize that, with stronger anti-cyclonic circulation within the bulge, more water recirculates in the bulge.

The aim of the present paper is to provide additional evidence of a well-developed anti-cyclonically rotating river bulge, using consecutive optical remote sensing images from a non-tidal sea, and to assess current theoretical understanding of river bulge internal structure and dynamics from the complementary numerical model simulation results. We focus on the evolution of an anti-cyclonically rotating bulge during one life-cycle, i.e. from its formation until its dilution with ambient water. The horizontal expansion of the bulge from remote sensing imagery and the reproduction by numerical simulation are compared with modelled undisturbed bulge development and existing theoretical knowledge. The bulge depth, volume of the river water trapped in the bulge and the movement of the bulge centre are evaluated from model experiments. The validity of gradient wind (or cyclostrophic) balance (see Eq. 2 below) is evaluated for specific time instants in the mid-field region of the plume.

The eastern sub-basin of the Baltic Sea, the Gulf of Riga (GoR), is used as the study area (Fig. 1a). The GoR is almost bowl-shaped, has brackish water and is semi-enclosed (connection to the Baltic Sea through the Irbe Strait, $25 \mathrm{~m}$ deep, minimum cross-section area $0.4 \mathrm{~km}^{2}$ and, through the Virtsu Strait which is $5 \mathrm{~m}$ deep, a minimum cross-section area of $0.04 \mathrm{~km}^{2}$ ). The circulation in the GoR is mainly driven by wind forcing and three-dimensional density gradient forcing (Raudsepp et al., 2003; Soosaar et al., 2014b; Lips et al., 2016). The mean circulation in spring consists of two main gyres, with the cyclonic gyre covering the eastern part and the anti-cyclonic gyre covering the western part of the GoR (Soosaar et al., 2014b; Fig. 2). This two-gyre system may transform into a single anti-cyclonic gyre/cyclonic gyre covering most of the basin area during the warm/cold season (Lips et al., 2016). A small tidal oscillation (O [0.01-0.1 m]; Keruss and Sennikovs, 1999) allows us to consider it as a non-tidal estuary. The main freshwater source for the GoR is the Daugava River in the south-east, with a high discharge of $2500 \mathrm{~m}^{3} \mathrm{~s}^{-1}$ in early spring, which decreases to $200 \mathrm{~m}^{3} \mathrm{~s}^{-1}$ in late summer. The present study concentrates on the period from the last 12 days of March and early April 2007, when there was a high discharge of $\sim 2500 \mathrm{~m}^{3} \mathrm{~s}^{-1}$ and low wind.

\section{Materials and methods}

\subsection{Satellite data}

ENVISAT/MERIS (Medium Resolution Imaging Spectrometer) data with a $300 \mathrm{~m}$ resolution from the CoastColour database (http://www.coastcolour.org/data/archive/) were used for monitoring bulge dynamics and structure. MERIS was designed to monitor coastal waters (Doerffer et al., 1999) and, therefore, it has sufficient spectral resolution in the range of wavelengths above $555 \mathrm{~nm}$ for monitoring turbid and optically complex waters like the Baltic Sea (Gitelson et al., 2009). MERIS imagery was preferred to other similar sensors (e.g. MODIS) as (i) MERIS-based water quality retrievals in optically complex Case- 2 waters of the Baltic Sea are more accurate due to better performance of the atmospheric correction algorithm (Goyens et al., 2013). In addition, (ii) MERIS has a higher spatial resolution $(300 \mathrm{~m})$, which enables us to resolve detailed features of the river bulge. The MERIS images were processed using the Case-2 Regional (C2R) algorithm (Doerffer and Schiller, 2007, 2008) in the BEAM software package (http://www. brockmann-consult.de/cms/web/beam/) in order to apply atmospheric correction and to obtain the reflectance values used for TSM (total suspended matter) retrieval. The pixel quality flags/masks provided in the Level1 Coast Colour product and in the Level $2 \mathrm{C} 2 \mathrm{R}$ product were used to mask the invalid pixels affected by the following phenomena: land, whitecaps, sun glint, cloud, cloud shadow, snow and ice. The $\mathrm{C} 2 \mathrm{R}$ algorithm has been validated in various locations in the optically complex waters of the Baltic Sea, and it has proven to be suitable for water quality monitoring (e.g. Siitam et al., 2014; Attila et al., 2013; Vaičiūte et al., 2012). We used TSM concentrations as a marker to distinguish turbid river water from "clear sea water" as TSM shows a stronger contrast compared to other biological and physical parameters (SST - sea surface temperature - and CHL - chlorophyll). Moreover, a comparative study by Beltrán-Abaunza et al. (2014) showed that TSM concentrations are more accurately retrieved by different standard remote sensing algorithms (including $\mathrm{C} 2 \mathrm{R}$ ) than other water constituents. A total 

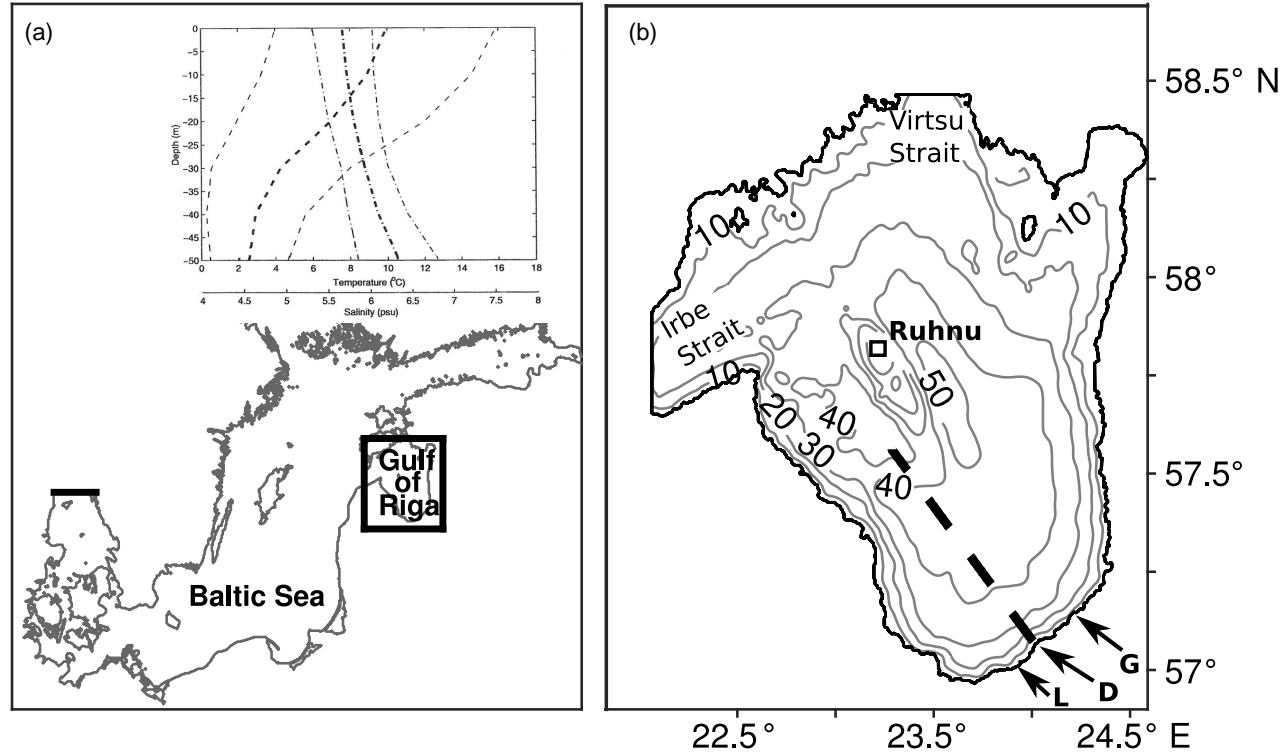

Figure 1. Map showing the location of the Gulf of Riga in the Baltic Sea (a). Embedded are mean (bold) temperature (dashed) and salinity (dash dotted) profiles with standard deviations (thin) from the central Gulf of Riga (adopted from Raudsepp, 2001). Topography of the Gulf of Riga (b). Arrows mark river mouth locations for the Daugava (D), Lielupe (L) and Gauja (G) rivers. The square shows the location of the weather station. The bold dashed line shows the transect of ferry-box measurements used for the model validation.
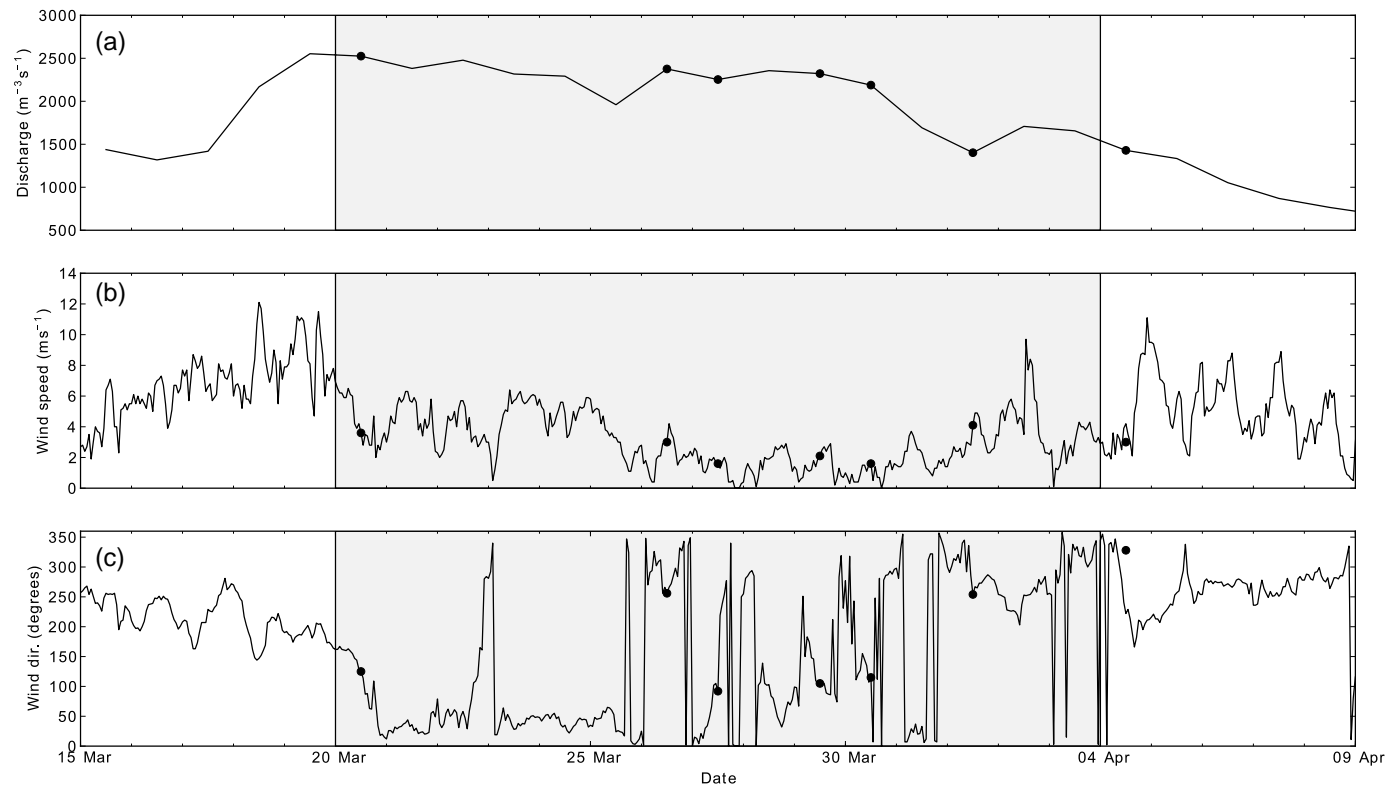

Figure 2. Time series of daily mean Daugava River discharge (a), hourly wind speed (b) and wind direction (c) measured at Ruhnu weather station. Black dots show time instants when satellite images were acquired. The grey area marks the period between the first and last available satellite image from the study period (20 March to 4 April).

of seven sufficiently cloud-free images was available from 20, 26, 27, 29, and 30 March and 1 and 4 April. The images were acquired at about 09:00 UTC. The satellite data were interpolated to a regular $0.3 \mathrm{~km} \times 0.3 \mathrm{~km}$ grid on the UTM$34 \mathrm{v}$ projection. Then the TSM concentrations were smoothed using a $3 \times 3$ point median filter.

\subsection{River runoff and wind data}

Daily volume flux for the Daugava River was measured $35 \mathrm{~km}$ upstream from the river mouth (coordinates $56.8516^{\circ} \mathrm{N}, 24.2728^{\circ} \mathrm{E}$ ). Daily volume flux for the Gauja and Lielupe rivers (see Fig. 1 for locations) was calculated 
from measured data. As the locations of measurement stations are 55 and $95 \mathrm{~km}$ from the river mouth, the measured data were multiplied by factors 1.05 and 1.87 respectively ${ }^{1}$, in order to obtain river discharge at the river mouth. The coefficients are obtained as a ratio between the whole catchment area of those rivers and the catchment area of those rivers up to the stations where the river flow was measured.

Wind data at $1 \mathrm{~h}$ intervals were obtained from Ruhnu weather station, which is located on the island of Ruhnu in the central area of the Gulf of Riga (Figs. 1 and 2).

\subsection{Numerical model set-up: GETM}

For numerical simulation we used the fully baroclinic and hydrostatic ocean GETM model (General Estuarine Transport Model, Burchard and Bolding, 2002) that is coupled to the GOTM (General Ocean Turbulence Model, Umlauf and Burchard, 2005) for vertical turbulence parameterization. The GETM uses a spherical coordinate system in the horizontal plane and a bottom-following vertical coordinate system. Using a mode splitting technique, GETM solves water dynamics on the Arakawa C-grid (Arakawa and Lamb, 1977). The GETM is characterized by advanced numerical techniques of advection schemes and internal pressure discretization schemes that minimize computational errors (Stips et al., 2004; Burchard and Rennau, 2008). In our setup we used the total variance diminishing (TVD) advection scheme for salinity, temperature and momentum (Pietrzak, 1998) and internal pressure parameterization suggested by Shchepetkin and McWilliams (2003). In our set-up we used the third-order monotone total variance diminishing (TVD) advection scheme with the P2-PDM limiter and a half-step directional split approach for salinity, temperature and momentum (Pietrzak, 1998; Klingbeil, 2014). Temporal discretization was conducted with a coupled explicit mode splitting technique for barotropic and baroclinic modes.

The model domain covered the GoR with closed boundaries at the Irbe Strait and the Virtsu Strait. In the study by Soosaar et al. (2014b), comparison of monthly mean circulations, with the Irbe and Suur straits being either closed or opened, showed only minor differences that occur mostly near the straits. The coefficient of determination between the two cases for April 1998 was $R^{2}=0.93$. Our analyses of model simulations concentrate on the south-eastern part of the GoR where the effect of closed straits is expected to be negligible over the simulation time period of 2 weeks. Topography was prepared using the Baltic Sea Bathymetry Database (BSHC, 2013) and interpolated to a $125 \mathrm{~m}$ regular grid. Depths at the head of Daugava were adjusted to include the Riga harbour fairway (depth $7 \mathrm{~m}$ ). The vertical water column was split into 30 density adaptive layers, giving a vertical resolution of under $0.5 \mathrm{~m}$ within the stratified bulge area

\footnotetext{
${ }^{1}$ Methodology worked out and in use for the Gauja and Lielupe rivers in LVGMC - Latvian Environment, Geology and Meteorology Centre Institute. http://www.meteo.lv/en/.
}

(Gräwe et al., 2015). The barotropic time step was $3 \mathrm{~s}$ and the baroclinic time step $60 \mathrm{~s}$. Hourly river runoff input from the measurements of three rivers, Daugava, Lielupe and Gauja, was included. Daugava runoff was equally distributed over seven grid cells. The meteorology was adopted from the EMCWF ERA-Interim data set with a lateral resolution of $1 / 4^{\circ}$ and a temporal resolution of $6 \mathrm{~h}$ (Dee at al., 2011).

The model simulation covered the period from $20 \mathrm{March}$ to 5 April 2007. Initial salinity fields were interpolated from the 1 nautical mile simulation for the Baltic Sea (Maljutenko and Raudsepp, 2014). The density only depended on salinity. A 3-day spin-up period with a realistic salinity field and a linear increase in river runoff from zero to the measured river runoff value on 20 March 2007 was used before including wind forcing on 20 March (real simulation). TSM was used as a passive tracer for the detection of river water spreading in the model simulation. The initial TSM concentration was set to zero in the GoR and the TSM concentration in river water was set to a unit value. The passive tracer was released into the GoR only as the Daugava River load of TSM, being proportional to the Daugava River runoff starting from 20 March.

\subsection{Model validation}

In situ measurements suitable for the model validation from the study area during high Daugava River runoff are ferrybox measurements on board the ship travelling between Riga and Stockholm. The available measurements for the estimation of the ability of the model to reproduce Daugava River bulge dynamics cover the period from 20 March to 4 April 2014. This period comprises the increase in the Daugava River runoff from $600 \mathrm{~m}^{3} \mathrm{~s}^{-1}$ to the peak value of $1100 \mathrm{~m}^{3} \mathrm{~s}^{-1}$ and the decrease in the runoff to $800 \mathrm{~m}^{3} \mathrm{~s}^{-1}$ (Fig. 3a). In total, eight transects from the Daugava River mouth to the central GoR with 2-day intervals fall into the period (Fig. 1). The model set-up for the validation run was made similarly to the one described in Sect. 2.3. The daily river runoff input from the measurements of the Daugava River was included. The meteorology was adopted from the HIRLAM-ETA data set, with a lateral resolution of $11 \mathrm{~km}$ and a temporal resolution of $3 \mathrm{~h}$ (Undén et al., 2002). Initial salinity fields were interpolated from the HIROMB 1 nautical mile simulation for the Baltic Sea on 20 March 2014 (Funkquist and Kleine, 2000). The density only depended on salinity. No spin-up period was included.

The mid-field bulge front can be characterized as the location of a maximum salinity gradient. We calculated the salinity gradient along the ship transect from measurements and model results. The maximum gradient location from in situ measurements stayed mostly at $5 \mathrm{~km}$ from the river mouth (Fig. 3c). There are two exceptions, on 29 March and 2 April, when the maximum gradient was located at $10 \mathrm{~km}$ (Fig. 3c) following a period of wind to the west (Fig. 3b). In the model simulation, the bulge front increased from $1 \mathrm{~km}$ on $21 \mathrm{March}$ 

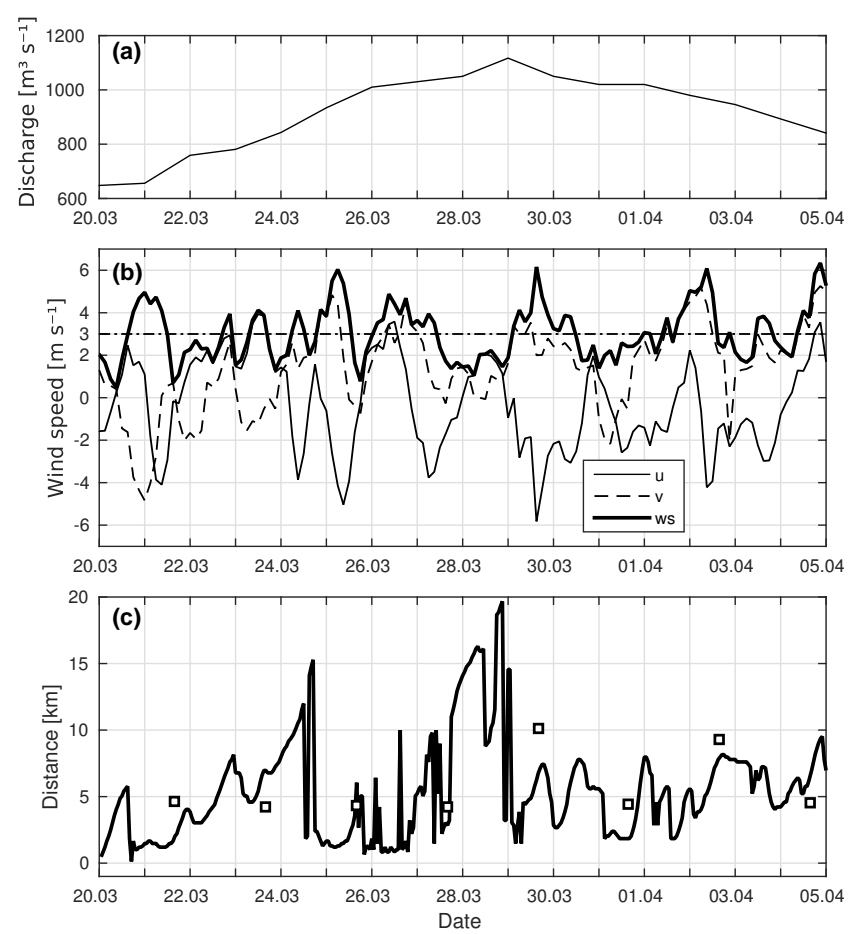

Figure 3. Time series of (a) daily mean Daugava River discharge; (b) $3 \mathrm{~h}$ wind speed (bold), eastern (solid) and northern (dashed) wind components from the HIRLAM-ETA data set at Ruhnu, and $3 \mathrm{~m} \mathrm{~s}^{-1}$ wind speed (dash dotted); (c) offshore location of the maximum salinity gradient from model (solid) and ship measurements (open square) for the period from 20 March to 5 April 2014. Distance is measured along the ship track from the mouth of the Daugava River.

to $15 \mathrm{~km}$ on $24 \mathrm{March}$. That period corresponded to the period of increase in river runoff and low winds (Fig. 3a, b). From the evening of 24 March the wind speed increased and the bulge was destroyed. The front retreated to a position at $1 \mathrm{~km}$ from the river mouth. The bulge started to increase on 27 March and reached a maximum extent of $20 \mathrm{~km}$ on the night of $28 \mathrm{March}$. This corresponded to a peak in river runoff and calm winds. During the rest of the simulation period, the bulge front remained between 2 and $10 \mathrm{~km}$. The root mean square deviation between the locations of simulated and observed bulge fronts was $2.4 \mathrm{~km}$.

\section{Results}

\subsection{Satellite imagery and model simulation}

The first satellite image on 20 March showed the development of three river plumes. The Daugava River plume was far larger (about $8 \mathrm{~km}$ in diameter) than the Gauja and Lielupe river plumes (Fig. 4a), which can also be seen in the numerical model (Fig. 4h). The wind conditions favoured the development of river plumes. From 15 to 19 March wind speed in- creased from 2 to $10 \mathrm{~m} \mathrm{~s}^{-1}$ (Fig. 2b), which could have generated sufficient mixing to destroy previously formed river plumes as well as prevent the development of a clearly distinguishable river plume. Just prior to the first satellite image, the wind speed dropped from 11 to $2 \mathrm{~m} \mathrm{~s}^{-1}$, which may have considerably reduced wind mixing and enabled the free development of river plumes. From 17 to 20 March Daugava River discharge increased from 1500 to $2500 \mathrm{~m}^{3} \mathrm{~s}^{-1}$ (Fig. 2a). The discharges of the Lielupe and Gauja rivers were 230 and $180 \mathrm{~m}^{3} \mathrm{~s}^{-1}$ respectively. The river plumes were quite distinguishable, as the ambient TSM concentration was $2 \mathrm{~g} \mathrm{~m}^{-3}$, compared to $20 \mathrm{~g} \mathrm{~m}^{-3}$ in the bulge centre, in the southern part of the GoR (Fig. 4a). In all three cases, the river water had most likely initially spread offshore, then turned to the right and formed a coastal current. In the bulge, current velocities were up to $50 \mathrm{~cm} \mathrm{~s}^{-1}$, while ambient currents were about $5 \mathrm{~cm} \mathrm{~s}^{-1}$ (Fig. 4h). All three plumes consisted of a bulge area and a coastal current (Fig. 4a). The coastal current was detached from the coast, leaving a stripe of lower TSM water near the coast (Fig. 4a, h). The offshore location of the maximum currents parallel to the coast and a countercurrent at the coast (Fig. 4h) were remnants of the previous spreading of river water along with wind- and density-driven currents in the GoR.

Checking the sequence of tracer spreading in the numerical model showed that the plume on 26 March was the result of the re-initiation of the river plume on $24 \mathrm{March}$. The winds of $6 \mathrm{~m} \mathrm{~s}^{-1}$ from the northeast had hampered the free development of the river plume by mixing river water and transporting it offshore. The Daugava River bulge had a diameter of $\sim 16 \mathrm{~km}$ (Fig. 4b). The core of the bulge was almost circular, with many intrusions along the outer rim. In the core of the bulge, freshly discharged water with a high TSM concentration formed a jet with an anti-cyclonic spreading pattern along the left side of the bulge. The existence of a coastal current could not be verified on the satellite image and the bulge manifested itself as more of a separate feature of the plume. The coastal current had formed as a narrow band pressed against the coast in the numerical model (Fig. 4i). As shown in Sect. 3.2, the northeasterly wind may push the bulge offshore and cause several intrusions at the open sea area of the bulge (Fig. 6b). Model simulation showed a strong background anti-cyclonic circulation of about $20 \mathrm{~cm} \mathrm{~s}^{-1}$ in the south-eastern GoR (Fig. 4i). The Gauja River plume consisted of a bulge area and a coastal current attached to the coast. The Lielupe River plume was almost undetectable, as the volume discharge had decreased to $130 \mathrm{~m}^{3} \mathrm{~s}^{-1}$.

During the next 4 days, i.e. until 30 March, the wind speed was very low, between 0 and $3 \mathrm{~ms}^{-1}$. We may assume that wind-driven currents and mixing were negligible. The Daugava River bulge remained almost circular and further detached from the coast (Fig. 4c-e, i-l). The main feature within the bulge was anti-cyclonically turning river water with a high TSM concentration (Fig. 4c-e) and a wellestablished anti-cyclonic circulation in the bulge, with a char- 

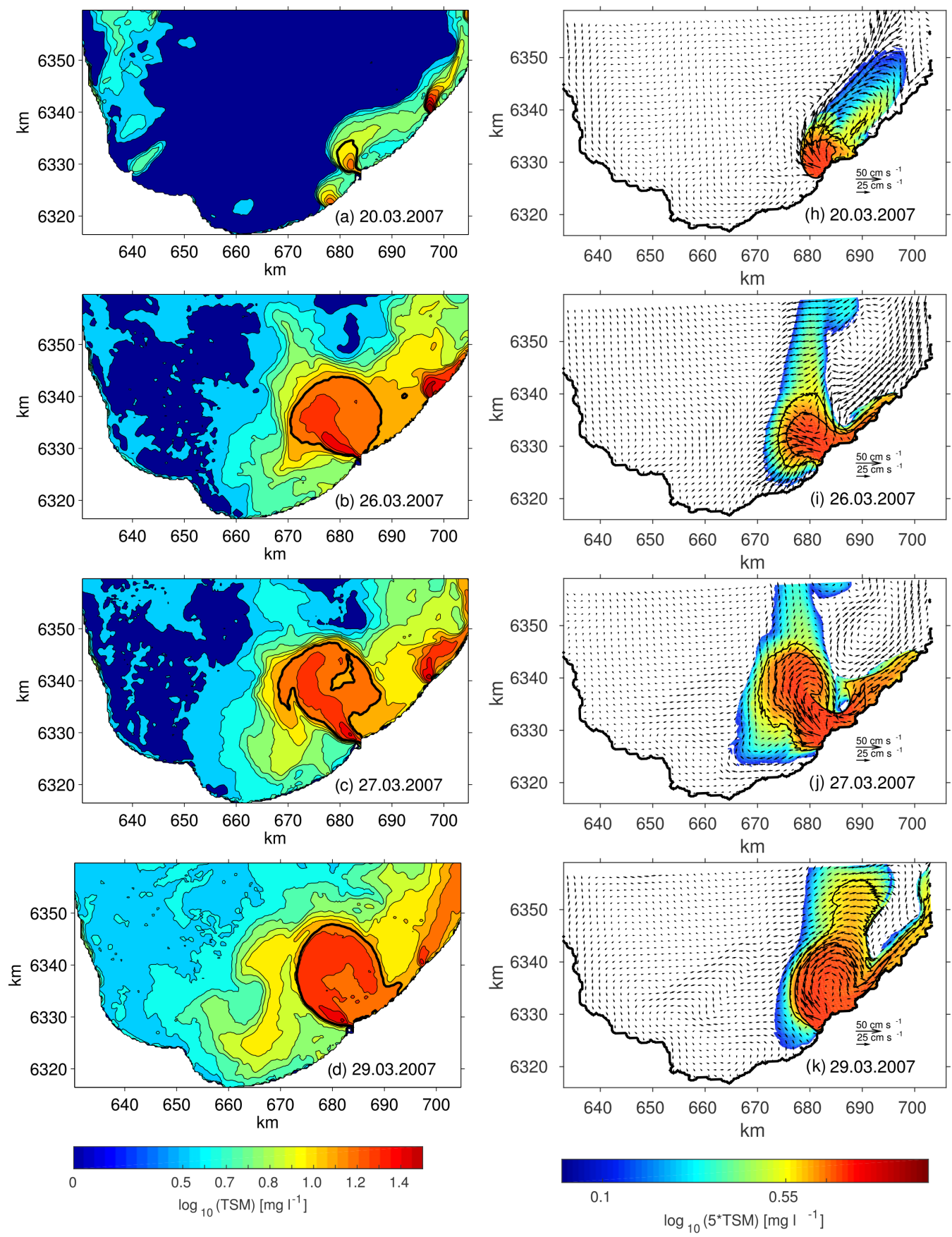

Figure 4.

acteristic current speed of $20 \mathrm{~cm} \mathrm{~s}^{-1}$ (Fig. 4i-1). This gives direct confirmation that water in natural buoyant bulges circulates anti-cyclonically in the Northern Hemisphere. More water intruded into the southern GoR at the western boundary of the bulge. Even weak onshore wind may cause significant intrusions at the western boundary of the bulge (Fig. 6d). This intrusion spread anti-cyclonically, probably due to ambient circulation, and diluted with surrounding water. No clear coastal currents were visible.

By 1 April, the wind speed had increased to $4 \mathrm{~m} \mathrm{~s}^{-1}$ and was blowing from the north. Daugava River discharge had decreased from $\sim 2000$ to $\sim 1500 \mathrm{~m}^{3} \mathrm{~s}^{-1}$ (Fig. 2). The image from 1 April still showed a circular bulge with a notably smaller TSM concentration than previously (Fig. 4f). The bulge had been transported westward and was nearly detached from the Daugava River outlet. The numerical model captured the tendency of westward transport of the bulge from 30 March to 1 April, but the bulge was more distorted 

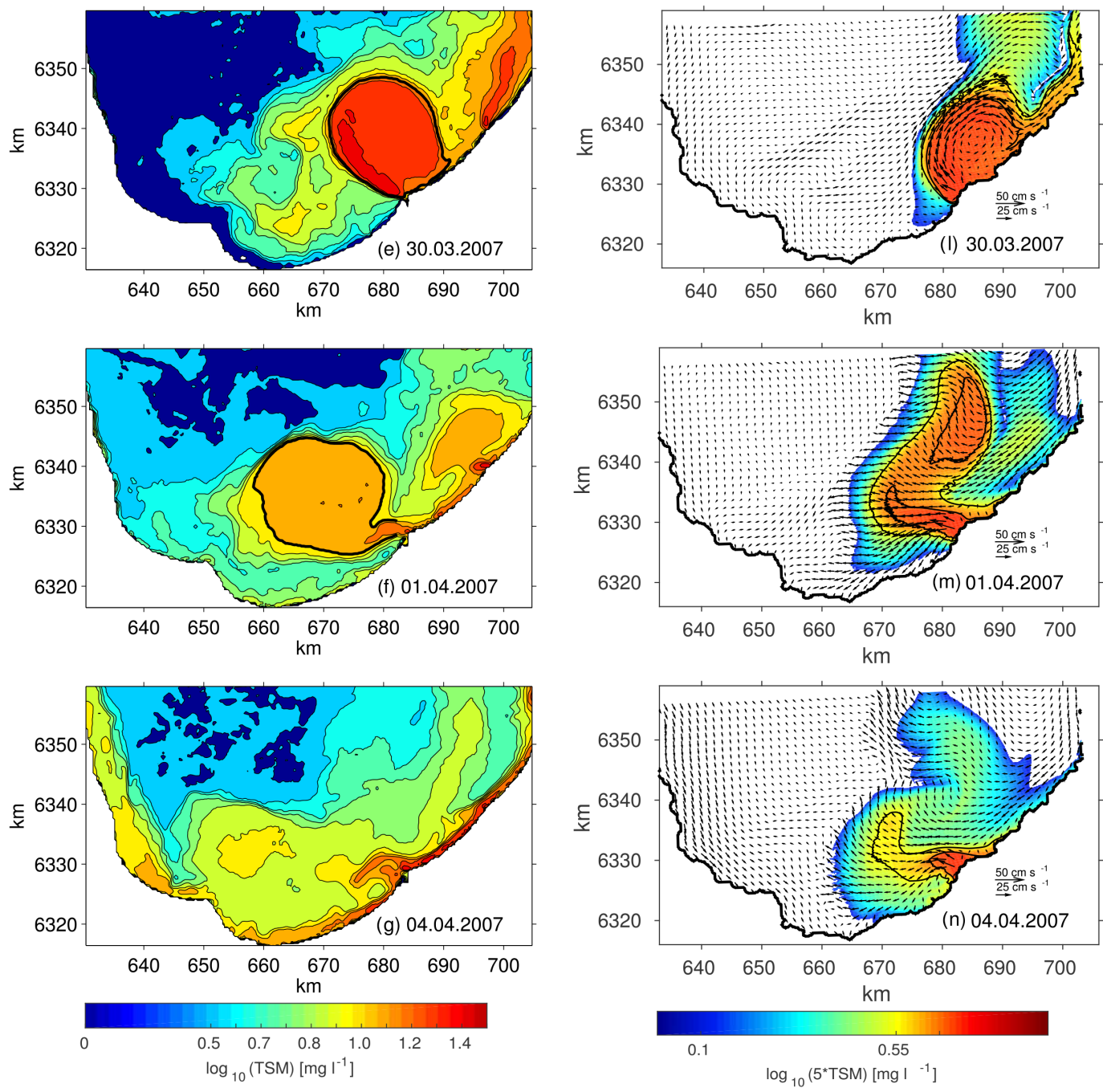

Figure 4. TSM concentration maps for the southern part of the Gulf of Riga from satellite images (left column) and TSM concentration and surface velocity maps from the numerical simulation (right column). The bold contours on the satellite images show the indicative edge of the Daugava River bulge. Black contours on the numerical model simulation maps represent TSM concentrations of $\log _{10}($ TSM $)=-0.15$ and $=-0.05$. The former is used for the determination of the Daugava River bulge. The coordinate system is on the UTM-34v projection (Cont.).

(Fig. 4m). The strong wind event of $10 \mathrm{~m} \mathrm{~s}^{-1}$ on 2 April had destroyed the bulge, and river water with a higher TSM concentration had smeared over the southern GoR by 4 April (Fig. 4g, n).

\subsection{Idealized simulations}

In the realistic model simulation, the Daugava River plume was affected by river discharge, ambient currents and winddriven currents. We performed numerical sensitivity tests with (1) river discharge into a stratified GoR, while wind forcing was switched off, and (2) river discharge into a homogeneous GoR with an ambient water salinity of $6 \mathrm{~g} \mathrm{~kg}^{-1}$, which is the long-term average value for the salinity in the central GoR (Raudsepp, 2001, Fig. 2b), while wind forcing was switched off (ideal simulation). In the first case, the anticyclonic bulge did not develop within the course of the model simulation and the coastal current was kept offshore due to ambient circulation (Fig. 5a). In the ideal run, river plume developed steadily into an anti-cyclonically recirculating bulge and a coastal current (Fig. 5b). The bulge length (offshore extent) and width (along-shore extent) as well as the width of the coastal current increased steadily in the course of the model simulation.

Additional simulations with cross-shore and alongshore winds were made with wind speeds of 2 and $4 \mathrm{~m} \mathrm{~s}^{-1}$. A wind speed of $2 \mathrm{~m} \mathrm{~s}^{-1}$ caused minor, if any, alterations in the case of all wind directions (not shown). A wind speed of $4 \mathrm{~m} \mathrm{~s}^{-1}$ altered the bulge in agreement with the classi- 

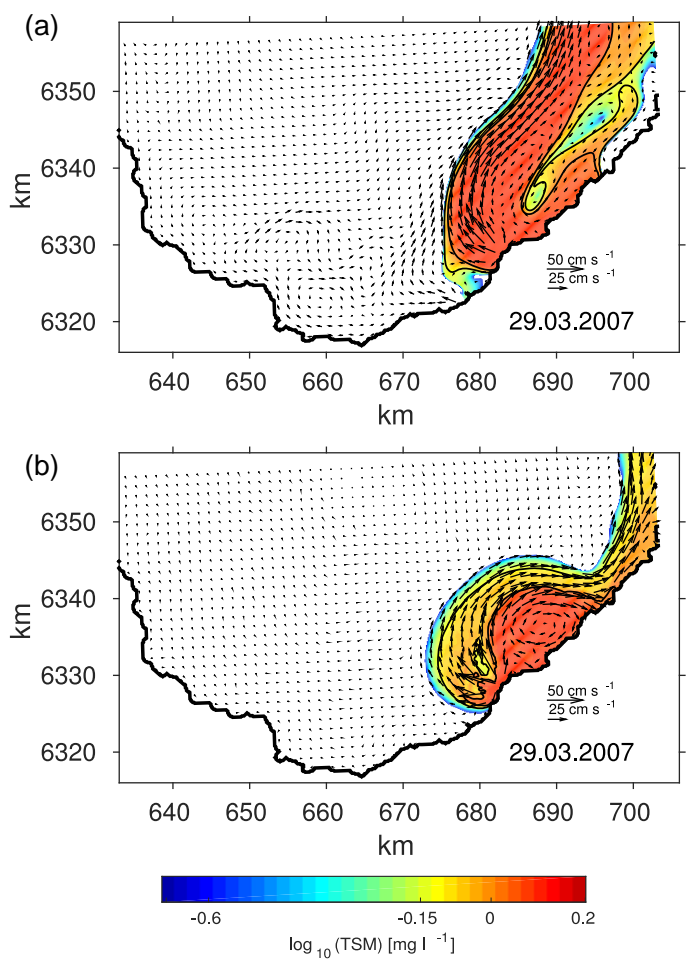

Figure 5. Instantaneous surface velocity and TSM concentration maps for simulation with realistic ambient density and no wind forcing (a) and idealized model simulation with uniform ambient density and no wind forcing (b) at noon on 29 March 2007. Solid lines represent TSM concentrations of $\log _{10}(\mathrm{TSM})=-0.15$ and $=-0.05$. The coordinate system is on the UTM-34v projection.

cal Ekman transport theory. The alongshore downwelling favourable wind pushed the bulge towards the coast and the coastal current was well developed (Fig. 6a). The alongshore upwelling favourable wind pushed the bulge offshore, so that the bulge was detached from the coast and no coastal current developed (Fig. 6b). The bulge had an irregular shape with several intrusions at the open sea area of the bulge. In the case of offshore wind, the bulge mid-field region was less uniform, closer to the coast, and coastal current was enhanced (Fig. 6c). Onshore wind tilted the bulge to the upcoast direction, with significant intrusions at the upcoast rim of the bulge (Fig. 6d). The coastal current was restrained and had an irregular shape. Thus, comparison of the real run with test cases showed a significant effect of wind in the evolution of the river bulge, even if wind speed was moderate (see Fig. 2b).

\subsection{Temporal evolution of the bulge}

The evolution of the river bulge is classically described by the spreading of the offshore front of the bulge and an increase in bulge depth (e.g. Avicola and Huq, 2003; HornerDevine et al., 2006). There are uncertainties in the determination of the edges of a bulge as well as the volume of a bulge.
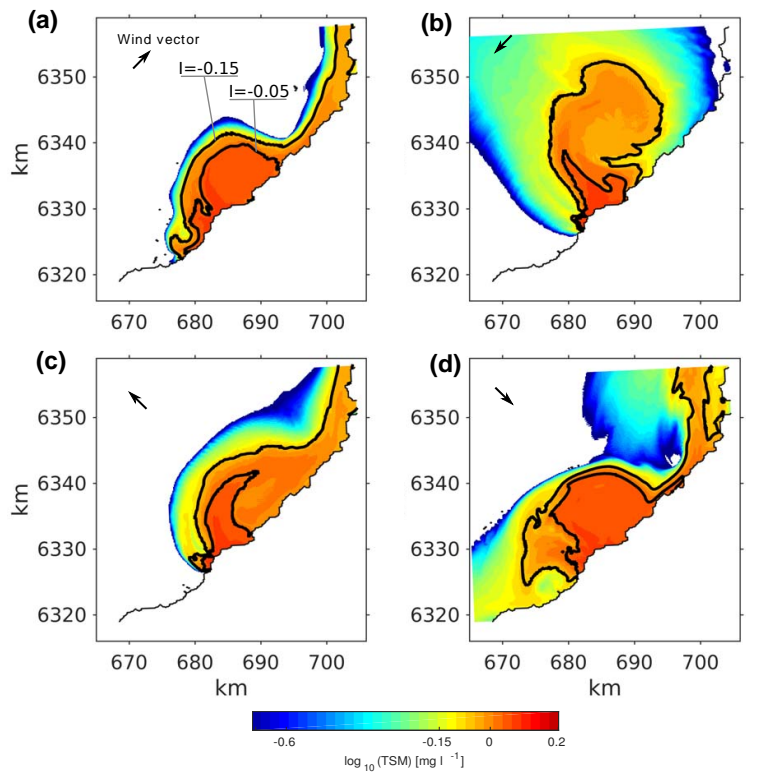

Figure 6. Instantaneous surface TSM concentration maps for simulation with uniform ambient density and a constant wind speed of $4 \mathrm{~m} \mathrm{~s}^{-1}$ blowing in a downstream (a), upstream (b), offshore (c) and onshore (d) direction at $6 T$ from the start of the simulation. Solid lines represent TSM concentrations of $\log _{10}(\mathrm{TSM})=-0.15$ and $=-0.05$. The coordinate system is on the UTM-34v projection.

In natural conditions, diffusion and mixing at the edges dilute river water with surrounding water (Horner-Devine et al., 2015). Multiple previous studies defined the bulge edge based on a preselected threshold value. Horner-Devine et al. (2006) chose a constant $20 \%$ buoyancy contour as the reference value. Gregorio et al. (2011) used a reference velocity, $1.7 \mathrm{~cm} \mathrm{~s}^{-1}$, to define the coastal current front. Soosaar et al. (2014a) defined the bulge edge as $10 \%$ of the discharge depth.

We used TSM concentration to define the bulge boundary. Our main criterion was to capture the circular part of the bulge and neglect coastal current as well as most of the intrusions. In the numerical model, the bulge boundary was defined where $I=\log _{10}(\mathrm{TSM})>-0.15$. Different values of $I>-0.05,-0.10,-0.20,-0.25$ were also used for the bulge boundary. The bulge radius and mean depth increased with decreasing $I$ (Fig. 7b for radius; mean depth not shown), but the dynamics of the bulge did not depend on the selected threshold value for the bulge boundary.

We compared the temporal evolution of mean depth, radius and volume of the real and ideal bulge from the numerical model. In order to be consistent with previous river bulge studies (Horner-Devine, 2009; Horner-Devine et al., 2006, 2008), the bulge effective radius, $r_{\mathrm{b}}$, was estimated through the area of the bulge, $A_{\mathrm{b}}$, assuming a circular shape of the bulge 

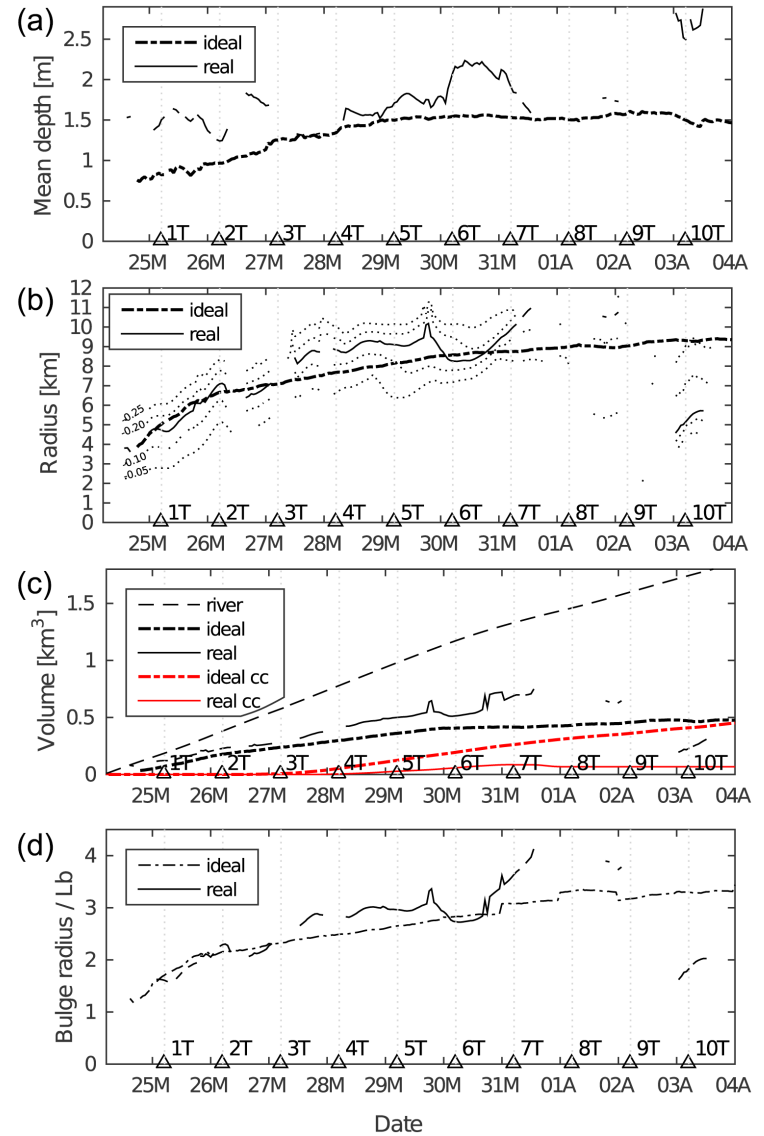

Figure 7. Time series of the Daugava River bulge mean depth (a), bulge radius (b), bulge volume (c) and the bulge effective radius scaled with the bulge Rossby radius (d). The solid line represents the real model simulation and the dash-dotted line the idealized model simulation. Time series of the bulge radius where the bulge is defined: $I=\log _{10}$ (TSM) $>-0.05 ;-0.10 ;-0.20 ;-0.25$ (dotted) (b). Time series of cumulative river water (dashed), bulge volume (black) and volume of the coastal current (red) in the real model simulation (solid) and ideal model simulation (dash-dotted) (c). Triangles represent the rotation period of the earth starting from 24 March 2007 05:00 GTM.

$r_{\mathrm{b}}=\left(\frac{A_{\mathrm{b}}}{\pi}\right)^{\frac{1}{2}}$.

According to the criterion of the bulge definition, the bulge is defined after about $0.5 T$, where $T$ is the rotation period of the earth (Fig. 7a, b) and $T=0 \equiv 24$ March 2007 05:00. A steady increase of the real bulge took place during seven rotation periods. Both mean depth and radius as well as the volume were larger for the real bulge than for the ideal bulge. We would like to note the pulsation of the real bulge - when bulge diameter increased, bulge mean depth decreased, and vice versa. The decrease in the bulge diameter was faster than the decrease in bulge mean depth during the dissipa- tion phase, which started from $7 T$. Occasionally, bulge depth even increased, implying that water in the bulge was mixed deeper during the dissipation phase.

The volume of river water that went into the bulge increased relatively quickly during the first two rotation periods (Fig. 7c). In the real case, almost $60 \%$ of river water was trapped inside the bulge, while in the ideal case the volume reached $45 \%$. We estimated the volume that was transported away by the coastal current. In order to be consistent with our bulge definition, we calculated water flow at the transect through the model grid cells where $I>-0.15$. During $2 T$, a negligible amount of river water was transported by the coastal current. During $2 T$ the fraction of river water inside the bulge decreased monotonically, while the volume of the coastal current increased (not shown). In the real case, water volume in the bulge increased until the bulge started to dissipate, but steadily retained its $50 \%$ river water content. The fraction of river water started to increase from $4 T$, but did not exceed $5 \%$ until the end of the simulation. In the case of the real bulge, our estimations showed that about $50 \%$ of river water could be determined as either coastal current or as bulge due to intrusions and mixing at the boundaries of the bulge and the coastal current (see Fig. 4), unless we broaden the definition of the bulge. Still, it is obvious from satellite images and simulation results that a far larger amount of river water stayed within the bulge and was transported offshore by intrusions than the amount that formed a coastal current. In the ideal bulge, the fraction of river water decreased after $2 T$, while the coastal current increased. During $11 T$, the fraction of the volume in the bulge and in the coastal current equilibrated. Thus, we may conclude that in the present case of the Daugava River plume, density- and wind-driven currents oppose the development of the coastal current.

The bulge radius was non-dimensionalized with the bulge Rossby radius

$L_{\mathrm{b}}=\left(\frac{2 Q g^{\prime}}{f^{3}}\right)^{\frac{1}{4}}$

where $Q$ is river runoff. In our case, the bulge Rossby radius varied between 2.7 and $3.1 \mathrm{~km}$ in time, according to the actual runoff of the Daugava River. Time series of increase in the non-dimensional bulge radius from numerical simulations are presented in Fig. 7d. We approximated the growth rate of the bulge radius using a power function. In the real case, we excluded the time period when the bulge started to dissipate, i.e. maintaining the values up to $8 T$. The real and ideal simulations gave $r_{\mathrm{b}} \sim t^{0.50 \pm 0.04}$ and $r_{\mathrm{b}} \sim t^{0.28 \pm 0.01}$, with the coefficients of determination being $R^{2}=0.90$ and $R^{2}=0.98$ respectively. Thus, in the real model simulation, the growth of the bulge radius was faster than in the ideal simulation. It can be explained by prevailing upwelling favourable winds (Fig. 2b, c) which even with a speed of 3-4 $\mathrm{m} \mathrm{s}^{-1}$ restrained the development of a coastal current and retained more water in the bulge (Fig. 6b). Using 


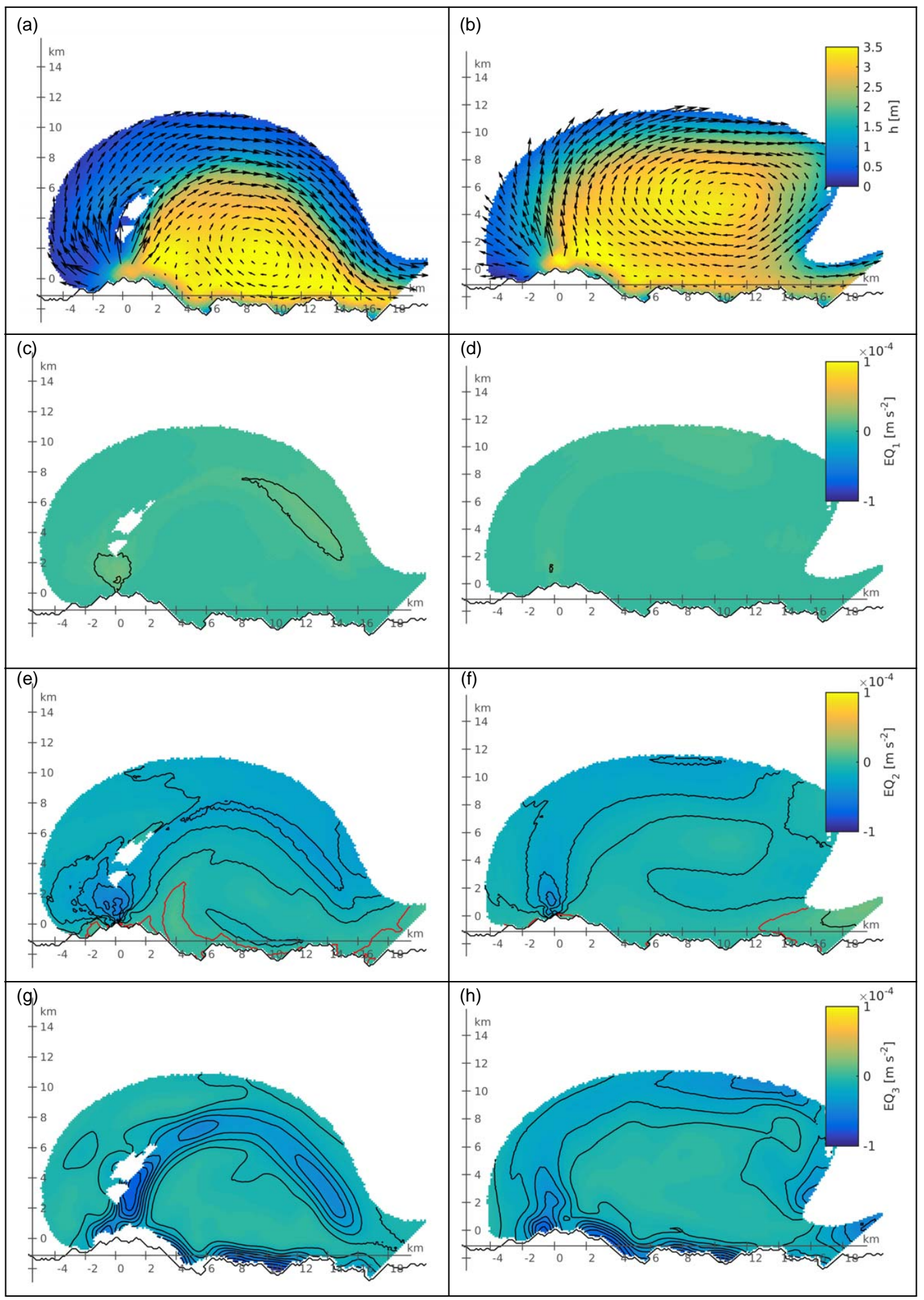

Figure 8.

thermal wind balance, Avicola and Huq (2003) estimated the growth rate of the bulge radius $r_{\mathrm{b}} \sim t^{1 / 4}$, although in the laboratory experiments they obtained the growth rate $r_{\mathrm{b}} \sim t^{2 / 5}$. From laboratory experiments, Horner-Devine et al. (2006) estimated that a buoyant surface advective bulge expands radially as $\sim t^{1 / 4}$ during the first five rotation periods, and later as $\sim t^{2 / 5}$. The measurement study for the Niagara River bulge (Horner-Devine et al., 2008) gave $\sim t^{0.46 \pm 0.29}$. 


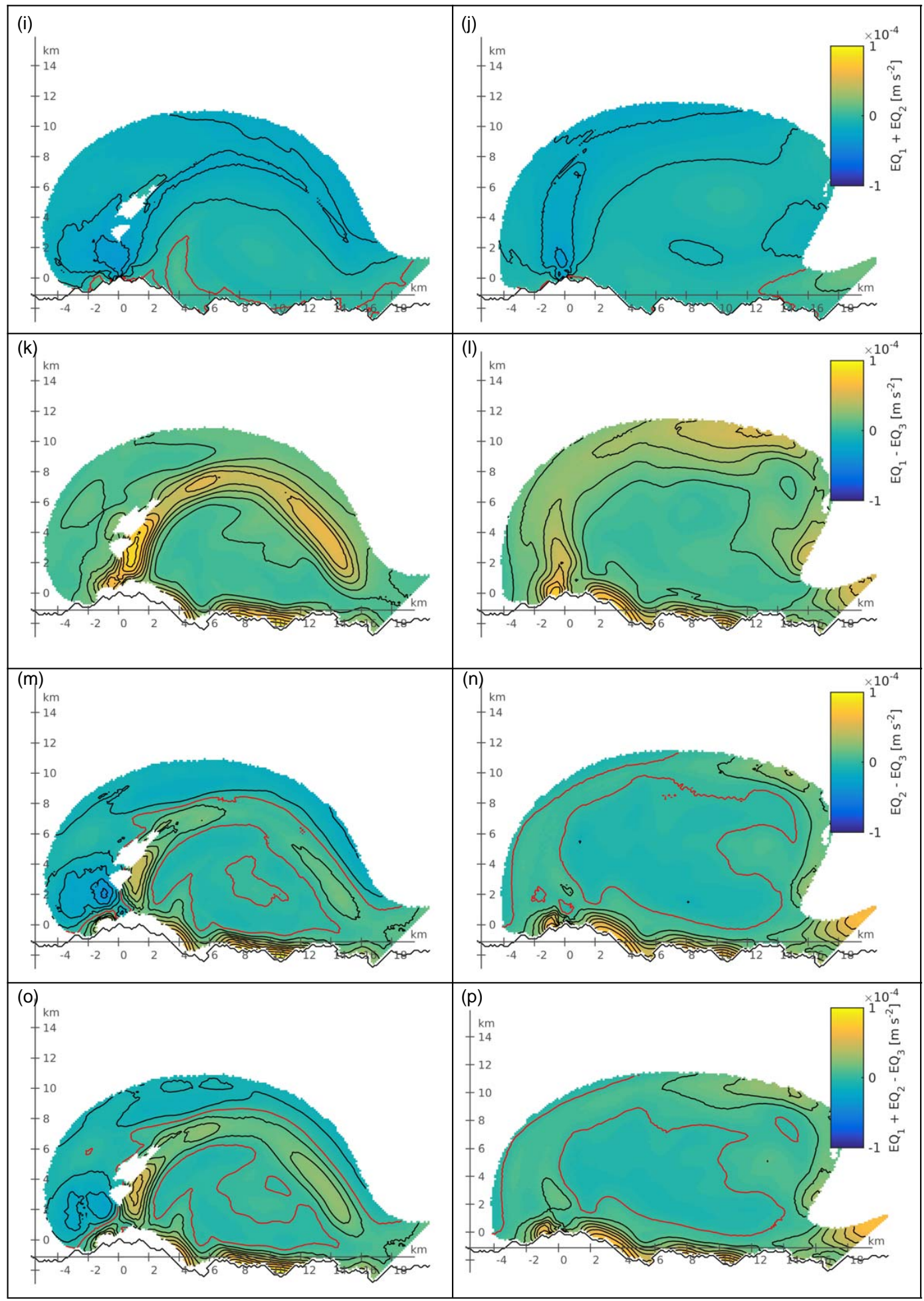

Figure 8. Bulge depth and depth averaged velocities, the terms $\left(T_{1}, T_{2}, T_{3}\right)$ of the balance (see Eq. 3) and the combinations of the terms for idealized (left column) and realistic (right column) model simulations on 29 March 2007 at 20:00. Bulge depth and depth averaged velocities (a-b), centrifugal term $\left(T_{1}\right)(\mathbf{c}-\mathbf{d})$, Coriolis term $\left(T_{2}\right)(\mathbf{e}-\mathbf{f})$, pressure gradient term $\left(T_{3}\right)(\mathbf{g}-\mathbf{h}), T_{1}+T_{2}(\mathbf{i}-\mathbf{j}), T_{1}-T_{2}(\mathbf{k}-\mathbf{l}), T_{2}-T_{3}(\mathbf{m}-\mathbf{n})$ and $T_{1}+T_{2}-T_{3}(\mathbf{o}-\mathbf{p})$. The contour interval is $1 \mathrm{~m} \mathrm{~s}^{-2}$. The red isoline represents zero. The blank area within the bulge is where the tracer concentrations were below the threshold values of the bulge definition (see text for bulge definition). The origin of the coordinate system is at the mouth of the Daugava River. True north is shown with the arrow (Cont.). 


\subsection{Bulge momentum balance}

The dynamics of the river bulge are described as a balance between centrifugal, Coriolis and pressure gradient terms:

$\frac{v_{\theta}^{2}}{r}+f v_{\theta}=g^{\prime} \frac{\partial h}{\partial r}$,

as hypothesized by Yankovsky and Chapman (1997) and confirmed by Horner-Devine (2009) for the Columbia River plume. In Eq. (3), the $v_{\theta}$ is depth averaged angular velocity, $r$ is radial distance from the bulge centre, $f$ is Coriolis' parameter, $g^{\prime}$ is reduced gravity and $h$ is bulge thickness. The left side of the equations contains the centrifugal $(T 1)$ and Coriolis ( $T 2)$ terms respectively; the right side of the equation is the pressure gradient term (T3). We calculated these terms for the case of the real bulge and the ideal bulge development on 29 March 2007 at 20:00 (Fig. 8). As was the case previously, the bulge was defined where $I>-0.15$. The currents were strongest at the steepest slope of the bulge (Fig. 8a, b). Although the ideal and real bulges were similar quantitatively, the bulge centre was much closer to the coast $(3 \mathrm{~km})$ for the ideal bulge than for the real bulge $(6 \mathrm{~km})$. The outer thin area of the ideal bulge was wider than in the case of the real bulge. All terms in Eq. (3) showed higher absolute values at the steepest slope of the bulge (Fig. 8c-h). With the exception of the near-field region, the centrifugal force was nearly an order of magnitude smaller than the Coriolis' term and the pressure gradient term. Geostrophic balance was valid for the entire mid-field of the bulge (Fig. 8m, n). Taking into account the balance, (Eq. 3), the error even increased slightly (Fig. 8o, p).

We calculated the time series of spatially averaged momentum balance terms, Eq. (3), for the ideal bulge (Fig. 9a) and the real bulge (Fig. 9b). In the case of the ideal bulge, all three terms contributed significantly to the momentum balance during the initial phase of bulge development, i.e. up to $1 T$ (Fig. 9a). Between $1 T$ and $2 T$ the contribution from the centrifugal force decreased, so that this term became nearly an order of magnitude smaller than the Coriolis term and the pressure gradient term. In the case of the real bulge, the centrifugal force also decreased during $1 T$ and $2 T$ (Fig. 9b). However, already at the beginning, the initial value of the centrifugal force was an order of magnitude smaller than the Coriolis and pressure terms. The Coriolis and pressure gradient terms do not have clear increasing or decreasing trends.

\section{Discussion}

A prominent feature in the satellite images and the model simulations was a well-developed anti-cyclonic circulation in the river bulge, which persisted for about 7-8 days. High river discharge and low wind conditions enabled undisturbed development of the bulge. The ideal model simulation showed that the bulge continued to develop steadily for
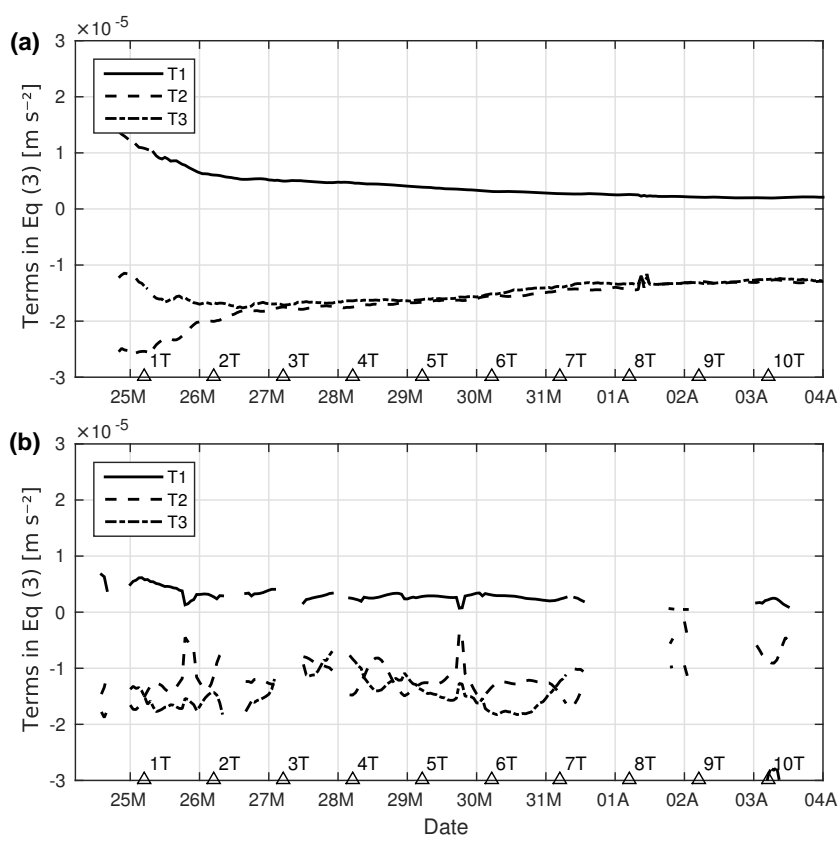

Figure 9. Time series of spatially averaged momentum balance terms (see Eq. 3): centrifugal term $\left(T_{1}\right)$ (solid), Coriolis term $\left(T_{2}\right)$ (dashed), and pressure gradient term $\left(T_{3}\right)$ (dash dotted) for ideal (a) and real (b) bulges. Triangles represent the rotation period of the earth starting from 24 March 2007, 05:00.

at least 10 rotation periods. Horner-Devine et al. (2006) argue that in the case of high inflow, i.e. a large Froude number, $\operatorname{Fr}=U\left(g^{\prime} H\right)^{-1 / 2}$, where $U=Q(H W)^{-1}, W$ is river width and $H$ is river depth; the plume becomes unstable after five to six rotation periods. In our case, the Froude number stayed between 0.9 and 1.5 during the whole modelling pe$\operatorname{riod}(W=700 \mathrm{~m}, H=7 \mathrm{~m}$ ). The plume was also stable in the numerical experiments of Nof and Pichevin (2001) and Fong and Geyer (2002).

We estimated the movement of the bulge centre in the ideal simulation. The bulge centre moved steadily to the north, completing about $8 \mathrm{~km}$ during nine rotation periods (Fig. 10a). As the centre also moved downstream, the actual offshore reach of the centre was $6 \mathrm{~km}$. The radius of the ideal bulge increased from 4 to $9 \mathrm{~km}$ from $0.5 T$ to $10 T$. Thus, by the end of our simulation, the ratio of the bulge centre, $y_{\mathrm{c}}$, to the bulge radius was less than 0.7 , which according to Horner-Devine et al. (2006) means that the bulge does not separate from the wall and that flow into the coastal current does not decrease. The latter was evident from our numerical simulation with the ideal bulge.

The movement of the real bulge centre was more "chaotic" (Fig. 10b). At each $1 \mathrm{~h}$ time step, the bulge centre was defined if the anti-cyclonic circulation with closed streamlines existed (i.e. Fig. 4k). When ambient current overrode bulge circulation, the bulge centre was not defined (i.e. Fig. 4i), although the bulge still existed if we look at the distribution 


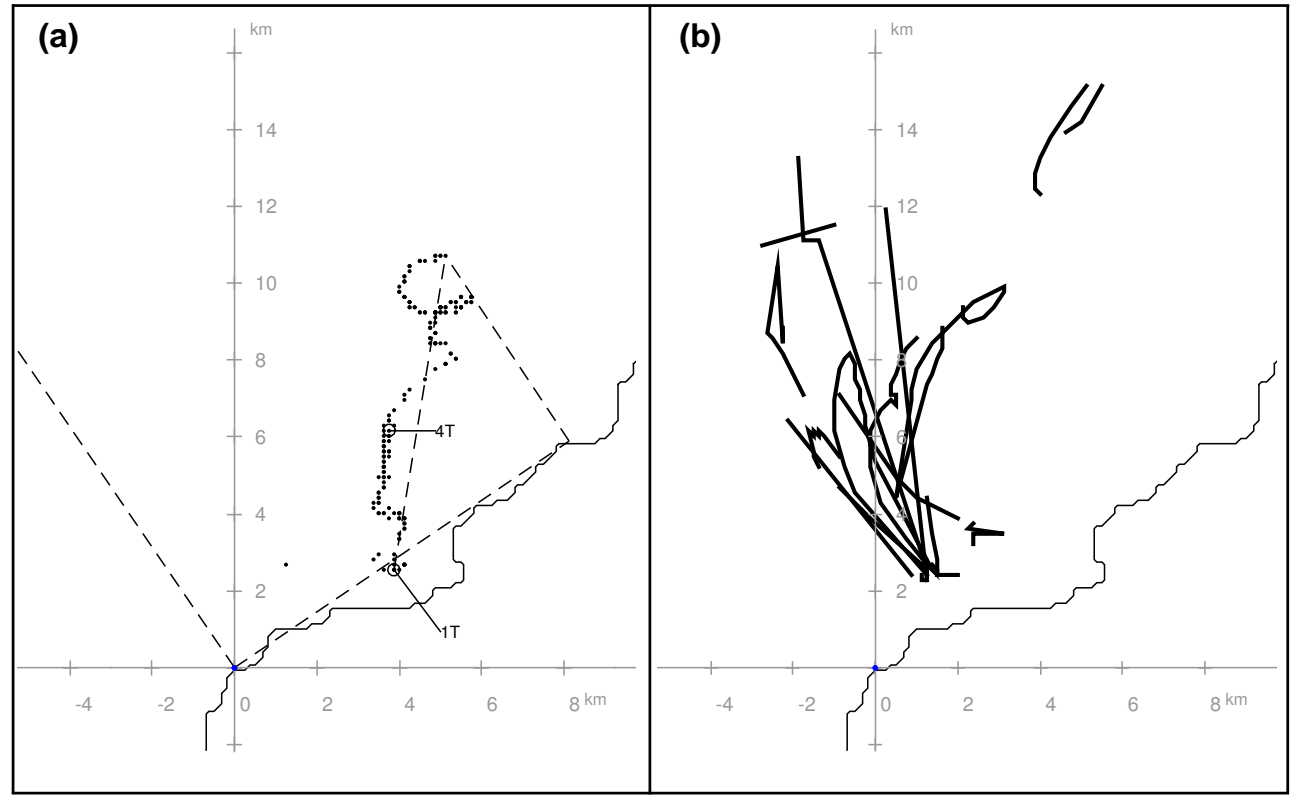

Figure 10. The trajectories of the bulge centre for the idealized simulation (a) and the realistic simulation (b) from 24 March 2007 05:00 to 5 April 2007 00:00. Each dot shows the location of the bulge centre at hourly intervals. Dashed lines show the normal and tangent to the coastline, the distance of the bulge centre from the location at $1 T$ up to the end of the simulation, and the distance of the bulge centre at the end of the simulation to the coast in the direction of the normal to the coast. $1 T$ and $4 T$ show the location of the bulge centre after one and four rotation periods of the earth starting from 24 March 2007 05:00 (a). Discontinuities in the bulge trajectories for the realistic model simulation exist because the bulge centre was defined only if anti-cyclonic circulation with closed streamlines was present (b).

of the tracer concentration. Thus, the movement of the bulge centre was not followed continuously. The main feature in the movement of the bulge centre was offshore-onshore oscillations (Fig. 10b). This behaviour is somewhat similar to bulge pinch-off described by Horner-Devine et al. (2006). Horner-Devine et al. (2006) proposed the ratio of internal radius, $L_{\mathrm{i}}=U / f$, to the bulge Rossby radius, $L^{*}=L_{\mathrm{i}} / L_{\mathrm{b}}$, to estimate bulge behaviour. In the case of the Daugava discharge, that ratio was between 0.81 and 1.26 , which corresponds to situations where the bulge is forced offshore relative to its radius (Horner-Devine et al., 2006, Fig. 17d-g). In the case of a high Froude number and/or low $g^{\prime}$ (in our case, $0.045 \mathrm{~m} \mathrm{~s}^{-2}$ ), the bulge becomes unstable and the flow to the coastal current is reduced (Horner-Devine et al., 2006). The behaviour of the Daugava River bulge from satellite images and the real numerical model simulation (Fig. 4) showed that river water was mainly contained in the bulge and that there were numerous intrusions at the outer perimeter of the bulge, which is qualitatively similar to the bulge behaviour in the model simulation by Horner-Devine et al. (2006, his Fig. 14).

Horner-Devine et al. (2015) summarize the results of the volume fraction going into a coastal current relative to river discharge, depending on inflow Rossby number. A relatively high Rossby number $\mathrm{O}$ [1] implies that most freshwater stays in the bulge, while a lower Rossby number would imply that there is less water going into the bulge and more into the coastal current. In the Daugava River outflow, the inflow
Rossby number varied between 3.4 and 5.7, which suggests that almost all of the river water should have been trapped in the bulge. Our estimates from the numerical model calculation showed that the fraction of river water that formed a coastal current was up to 10 times smaller than the amount of river water that remained in the bulge. In the ideal case, considerable volume went into the coastal current, although $Q$, Fr, Ro and $g^{\prime}$ were the same for ideal and real model simulations.

The explanation for the discrepancy between the ideal bulge and laboratory experiments could be the different behaviour of the plume in a near-field region. In a near-field region, river flow has a lift-off point in the location where river water detaches from the bottom and the upper layer Froude number is equal to one (Horner-Devine et al., 2015). At the lift-off point, vertical velocities cause shoaling of the plume interface and acceleration of the upper layer flow in a more seaward region. This, in turn, increases the Froude number, resulting in intense vertical mixing. In our idealized numerical simulation, the lift-off occurred at about $0.5 \mathrm{~km}$ from the river mouth (Fig. 8a). The most intensive mixing started at $1 \mathrm{~km}$ from the coast where tracer concentrations were below the limit of the bulge definition (white area in Fig. 8a and low tracer concentration in Fig 5a). The intensive mixing suppressed horizontal flow and the current velocities were low right behind the intense mixing zone, while the current velocities were higher at the left and right sides of the mixing 
zone (Fig. 8a). Thus, the intensive mixing zone created a barrier for the river water flow and split it into two jets. The jet on the right formed a rotating bulge. As the barrier altered the flow direction, the flow angle was notably smaller than $90^{\circ}$, resulting in a bulge centre located closer to the coast (Avicola and Huq, 2003). The jet on the left remained on the outer edge of the bulge. Such a barrier region is not observed in laboratory simulations. Natural buoyant river plumes have a small vertical to horizontal aspect ratio, $\mathrm{O}\left(10^{-3}\right)$, where vertical turbulent flux of density is considered to be dominant over horizontal turbulent fluxes (Horner-Devine et al., 2015). For laboratory simulations, the aspect ratio is at least an order of magnitude smaller. Horizontal turbulence flux would be comparable in magnitude to vertical mixing, and a sharply separated region of intense mixing is far less likely to form. In addition, in our numerical simulations, the Daugava River runoff was smeared over five horizontal grid points right at the coast, which enables a better resolution of the river plume in the near field than, for instance, that achieved by Hetland and Signell (2005).

In the case of the realistic model simulation, wind mixing overpowered the local mixing, thereby avoiding the creation of the barrier region. The density-driven and wind-forced background currents restricted the development of a plume coastal current and pushed the river bulge offshore. As a result, the bulge centre was further away from the coast (see Fig. 10b).

\section{Conclusions}

Satellite TSM images showed a clearly formed river bulge from the Daugava River discharge during the studied low wind period. Satellite images also confirmed anti-cyclonic rotation inside the bulge. The bulge grew up to $20 \mathrm{~km}$ in diameter before being diluted. A high-resolution numerical model simulation repeated the plume behaviour satisfactorily and enabled a detailed study of the bulge dynamics. While previous studies conclude that balance in Eq. (3) is valid for the bulge, our study showed that geostrophic balance is valid for the entire mid-field of the bulge except during 1-1.5T at the beginning of the bulge formation. Comparison of realistic and idealized model simulations showed a significant effect of wind-driven and density-driven circulation in the evolution of the river bulge, even if the wind speed was moderate.

The bulge radius was non-dimensionalized with the bulge Rossby radius. The real model simulation (measured wind and realistic ambient density) and the ideal simulation with no wind and uniform ambient density gave $r_{\mathrm{b}} \sim t^{0.50 \pm 0.04}$ and $r_{\mathrm{b}} \sim t^{0.28 \pm 0.01}$, with the coefficients of determination being $R^{2}=0.90$ and $R^{2}=0.98$ respectively. The bulge spreading rates agree well with laboratory experiments $\left(\sim t^{1 / 4}\right.$ by Horner-Devine et al., 2006) and fit in the margin of the Niagara River bulge study $\left(\sim t^{0.46 \pm 0.29}\right.$ by Horner-Devine et al., 2008).
Mean depth and radius as well as the volume were larger for the realistic model bulge than for the idealized bulge. River bulge behaviour from satellite images and the real numerical model simulation showed that river water is mainly contained in the bulge and there were numerous intrusions at the outer perimeter of the bulge caused by prevailing upwelling favourable and onshore winds. The fraction of river water that formed a coastal current was up to 10 times smaller than the amount of river water that remained in the bulge.

In the ideal simulation, considerable volume went into the coastal current, although $Q, \mathrm{Fr}$, Ro and $g^{\prime}$ were the same for ideal and real model simulations. The ideal numerical model simulation showed that in the case of a high inflow Rossby number, the river inflow might split into two jets in the plume near-field region, with a strong mixing zone in-between. Although the ideal and real bulges were similar,the splitting of the outflow into two jets caused the bulge centre to be closer to the coast in the case of the ideal bulge than in the case of the real bulge.

Acknowledgements. Volume flux data for the Gauja and Lielupe rivers were provided by state limited liability company Latvian Environment, Geology and Meteorology Centre in Riga, Latvia. Volume flux data for the Daugava River were provided by Latvenergo AS (a state joint stock company that provides electricity for the country's citizens). The work was financially supported by institutional research funding IUT (19-6) of the Estonian Ministry of Education and Research.

Edited by: J. M. Huthnance

\section{References}

Arakawa, A. and Lamb, V. R.: Computational design of the basic dynamical processes of the UCLA General Circulation Model, Meth. Comput. Phys., 17, 173-263, 1977.

Attila, J., Koponen, S., Kallio, K., Lindfors, A., Kaitala, S., and Ylöstalo, P.: MERIS Case II water processor comparison on coastal sites of the northern Baltic Sea, Remote Sens. Environ., 128, 138-149, 2013.

Avicola, G. and Huq, P.: The characteristics of the recirculating bulge region in coastal buoyant outflows, J. Mar. Res., 61, 435463, 2003.

BSHC (Baltic Sea Hydrographic Commission): Baltic Sea Bathymetry Database version 0.9.3., available at: http://data. bshc.pro/ (last access: 8 March 2016), 2013.

Beltrán-Abaunza, J. M., Kratzer, S., and Brockmann, C.: Evaluation of MERIS products from Baltic Sea coastal waters rich in CDOM, Ocean Sci., 10, 377-396, doi:10.5194/os-10-377-2014, 2014.

Burchard, H. and Bolding, K.: GETM - a general estuarine transport model, Scientific documentation, Technical Report EUR 20253 EN, European Commission, 2002.

Burchard, H. and Rennau, H.: Comparative quantification of physically and numerically induced mixing in ocean models, Ocean Modelling, 20, 293-311, 2008. 
Chant, R. J., Wilkin, J., Zhang, W., Choi, B.-J., Hunter, E., Castelao, R., Glenn, S., Jurisa, J., Schofield, O., Houghton, R., Kohut, J., Frazer, T. K., and Moline, M. A.: Dispersal of the Hudson River plume in the New York Bight: Synthesis of observational and numerical studies during LaTTE, Oceanography, 21, 148-161, 2008

Dee, D. P., Uppala, S. M., Simmons, A. J., Berrisford, P., Poli, P., Kobayashi, S., Andrae, U., Balmaseda, M. A., Balsamo, G., Bauer, P., Bechtold, P., Beljaars, A. C. M., van de Berg, L., Bidlot, J., Bormann, N., Delsol, C., Dragani, R., Fuentes, M., Geer, A. J., Haimberger, L., Healy, S. B., Hersbach, H., Holm, E. V., Isaksen, L., Kallberg, P., Köhler, M., Matricardi, M., McNally, A. P., Monge-Sanz, B. M., Morcrette, J.-J., Park, B.-K., Peubey, C., de Rosnay, P., Tavolato, C., Thepaut, J.-N., and Vitart, F.: The ERA-Interim reanalysis: configuration and performance of the data assimilation system, Q. J. Roy. Meteor. Soc., 137, 553-597, 2011.

Doerffer, R. and Schiller, H.: The MERIS case 2 water algorithm. Int. J. Remote Sens., 28, 517-535, 2007.

Doerffer, R. and Schiller, H.: MERIS Regional Coastal and Lake Case 2 Water Project atmospheric correction ATBD (Algorithm Theoretical Basis Document), 1.0, 41 pp., 2008.

Doerffer, R., Sorensen K., and Aiken, J.: MERIS potential for coastal zone applications, Int. J. Remote Sens., 20, 1809-1818, 1999.

Dzwonkowski, B. and Yan, X.: Tracking of a Chesapeake Bay estuarine outflow plume with satellite-based ocean color data, Cont. Shelf Res., 25, 1942-1958, 2005.

Fernández-Nóvoa, D., Mendes, R., Decastro, M., Dias, J., SánchezArcilla, A., and Gómez-Gesteira, M.: Analysis of the influence of river discharge and wind on the Ebro turbid plume using MODIS-Aqua and MODIS-Terra data, J. Marine Syst., 142, 4046, 2015.

Fong, D. A. and Geyer, W. R.: The Alongshore Transport of Freshwater in a Surface-Trapped River Plume, J. Phys. Oceanog., 32, 957-972, 2002.

Funkquist, L. and Kleine, E.: An introduction to HIROMB, an operational baroclinic model for the Baltic Sea, Tech. Rep. SMHI, Norrköping, 2000.

Gitelson, A. A., Gurlin, D., Moses, W. J., and Barrow, T.: A biooptical algorithm for the remote estimation of the chlorophyll-a concentration in case 2 waters, Environ. Res. Lett., 4, 045003 doi:10.1088/1748-9326/4/4/045003, 2009.

Goyens, C., Jamet, C., and Schroeder, T.: Evaluation of four atmospheric correction algorithms for MODIS-Aqua images over contrasted coastal waters, Remote Sens. Environ., 131, 63-75, 2013.

Gräwe, U., Holtermann, P., Klingbeil, K., and Burchard, H.: Advantages of vertically adaptive coordinates in numerical models of stratified shelf seas, Ocean Model., 92, 56-68, 2015.

Gregorio, S. O., Haidvogelb, D. B., Thomasa, P. J., Taskinogluc, E. S., and Skeend, A. J.: Laboratory and numerical simulations of gravity-driven coastal currents: Departures from geostrophic theory, Dynam. Atmos. Oceans, 52, 20-50, 2011.

Hetland, R. D. and Signell, R. P.: Modelling coastal current transport in the Gulf of Maine, Deep-Sea Res. II, 52, 2430-2449, 2005.

Hopkins, J., Lucas, M., Dufau, C., Sutton, M., Stum, J., Lauret, O., and Channelliere, C.: Detection and variability of the Congo
River plume from satellite derived sea surface temperature, salinity, ocean colour and sea level, Remote Sens. Environ., 139, 365385, 2013.

Horner-Devine, A. R.: The bulge circulation in the Columbia River plume, Cont. Shelf Res., 29, 234-251, 2009.

Horner-Devine, A. R., Fong, D. A., Monismith, S. G., and Maxworthy, T.: Laboratory experiments simulating a coastal river inflow, J. Fluid Mech., 555, 203-232, 2006.

Horner-Devine, A. R., Fong, D. A., and Monismith, S. G.: Evidence for the inherent unsteadiness of a river plume: Satellite observations of the Niagara River discharge, Limnol. Oceanogr., 53 2731-2737, 2008.

Horner-Devine, A. R., Hetland, R., and Macdonald, D.: Mixing and Transport in Coastal River Plumes, Annu. Rev. Fluid Mech., 47, 569-594, 2015.

Keruss, M. and Sennikovs, J.: Determination of tides in Gulf of Riga and Baltic Sea. Proc. International Scientific Colloqium "Modelling of Material Processing”, Riga, 28-29 May 1999.

Klingbeil, K., Mohammadi-Aragh, M., Gräwe, U., and Burchard, H.: Quantification of spurious dissipation and mixing discrete variance decay in a finite-volume frame-work, Ocean Model., 81, 49-64, 2014.

Kudela, R. M., Horner-Devine, A. R., Banas, N. S., Hickey, B. M., Peterson, T. D., Lessard, E. J., Frame, E., Bruland, K. W., Lohan, M., Jay, D. A., Peterson, J., Peterson, B., Kosro, M., Palacios, S., and Dever, E. P.: Multiple trophic levels fueled by recirculation in the Columbia River plume, Geophys. Res. Lett., 37, L18607, doi:10.1029/2010GL044342, 2010.

Lips, U., Zhurbas, V., Skudra, M., and Väli, G.: A numerical study of circulation in the Gulf of Riga, Baltic Sea. Part I: Whole-basin gyres and mean currents, Cont. Shelf Res., 112, 1-13, 2016.

Maljutenko, I. and Raudsepp, U.: Validation of GETM model simulated long-term salinity fields in the pathway of saltwater transport in response to the Major Baltic Inflows in the Baltic Sea, in: IEEE Xplore: Baltic International Symposium (BALTIC), 2014 IEEE/OES, 27-29 May 2014, Tallinn Estonia, IEEE, $23-$ 31, 2014.

Mendes, R., Vaz, N., Fernández-Nóvoa, D., Silva, J., Decastro, M., Gómez-Gesteira, M., and Dias, J.: Observation of a turbid plume using MODIS imagery: The case of Douro estuary (Portugal), Remote Sens. Environ., 154, 127-138, 2014.

Nof, D. and Pichevin, T.: The Ballooning of Outflows, J. Phys. Oceanogr., 31, 3045-3058, 2001.

Pan, J., Gu, Y., and Wang, D.: Observations and numerical modeling of the Pearl River plume in summer season, J. Geophys. Res.Oceans, 119, 2480-2500, 2014.

Pietrzak, J.: The use of TVD limiters for forward-in-time upstreambiased advection schemes in ocean modeling, Mon. Weather Rev., 126, 812-830, 1998.

Raudsepp, U.: Interannual and seasonal temperature and salinity variations in the Gulf of Riga and corresponding saline water inflow from the Baltic Proper, Nordic Hydrology, 32, 135-160, 2001.

Raudsepp, U., Beletsky, D., and Schwab, D. J.: Basin-scale topographic waves in the Gulf of Riga, J. Phys. Oceanogr., 33, 1129 1140, 2003.

Saldías, G., Sobarzo, M., Largier, J., Moffat, C., and Letelier, R.: Seasonal variability of turbid river plumes off central Chile based 
on high-resolution MODIS imagery, Remote Sens. Environ., 123, 220-233, 2012.

Shchepetkin, A. F. and McWilliams, J. C.: A method for computing horizontal pressuregradient force in an oceanic model with a nonaligned vertical coordinate, J. Geophys. Res., 108, 3090, doi:10.1 029/2001JC001047, 2003.

Siitam, L., Sipelgas, L., and Uiboupin, R.: Analysis of natural background and dredging-induced changes in TSM concentration from MERIS images near commercial harbours in the Estonian coastal sea, Int. J. Remote Sens., 35, 6764-6780, 2014.

Stips, A., Bolding, K., Pohlmann, T., and Burchard, H.: Simulating the temporal and spatial dynamics of the North Sea using the new model GETM (general estuarine transport model, Ocean Dyn., 54, 266-283, 2004.

Soosaar, E., Hetland, R. D., Horner-Devine, A., Avener, M. E., and Raudsepp, U.: Offshore spreading of buoyant bulge from numerical simulations and laboratory experiments. In: IEEE Xplore: Baltic International Symposium (BALTIC), 2014 IEEE/OES, 27-29 May 2014, Tallinn Estonia, IEEE, 2014a.

Soosaar, E., Maljutenko, I., Raudsepp, U., and Elken, J.: An investigation of anticyclonic circulation in the southern Gulf of Riga during the spring period, Cont. Shelf Res., 78, 75-84, $2014 \mathrm{~b}$.

Thomas, P. J. and Linden, P. F.: Rotating gravity currents: smallscale and large-scale laboratory experiments and a geostrophic model, J. Fluid Mech., 578, 35-65, 2007.
Umlauf, L. and Burchard, H.: Second-order turbulence closure models for geophysical boundary layers. A review of recent work, Cont. Shelf Res., 2, 795-827, 2005.

Undén, P., Rontu, L., Jörvinen, H., Lynch, P., Calvo, J., Cats, G., Cuxart, J., Eerola, K., Fortelius, C., Garcia-Moya, J. A., Jones, C., Lenderink, G., McDonald, A., McGrath, R., Navascues, B., Nielsen, N. W., Ødegaard, V., Rodrigues, E., Rummukainen, M., Rõõm, R., Sattler, K., Sass, B. H., Savijörvi, H., Schreur, B. W., and Sigg, R., The, H., and Tijm, A.: HIRLAM-5 scientific documentation, available at: http://www.hirlam.org/ (last access: 8 March 2016), 2002.

Vaičiūtė, D., Bresciani, M., and Bučas, M.: Validation of MERIS Bio-Optical Products with In Situ Data in the Turbid Lithuanian Baltic Sea Coastal Waters, J. Appl. Remote Sens., 6, 063568-1063568-20, doi:10.1117/1.JRS.6.063568, 2012.

Valente, A. and Silva, J.: On the observability of the fortnightly cycle of the Tagus estuary turbid plume using MODIS ocean colour images, J. Marine Syst., 75, 131-137, 2009.

Whitney, M. and Garvine, R.: Wind influence on a coastal buoyant outflow, J. Geophys. Res., 110, C03014, doi:10.1029/2003JC002261, 2005.

Yankovsky, A. E. and Chapman, D. C.: A simple theory for the fate of buoyant coastal discharges, J. Phys. Oceanogr., 27, 13861401, 1997. 